\title{
Architectural Volition, or What Does Form Mean?
}

\author{
HANS R. MORGENTHALER \\ University of Colorado Denver
}

Contemporary architecture has distinct symbolic properties, which consist uniquely of forms. These do not represent space directly, but via a synthesizing understanding. Alois Riegl established empathy as the mental capacity capable to construct a spatial view from such designs. This method sees style as a social, not a material, construct.

Art historians have continued to elaborate Riegl's method, Kunstwollen, by screening this term through the lenses of many humanistic, as well as, social and natural scientific methodologies. Art historians have mainly attempted to shed light on this concept by applying it to the new art forms and media created after the 1960s. Major contributions include that viewing and understanding art is part of epistemology. Beauty, i.e., is no longer based on the human form. Art inserts itself into the living world and begins to cleanse humanity, which was the utopian goal of Modernity.

This paper attempts to propose how this more complex methodology can be used to explain contemporary architecture. The major contribution of late-20th-century architecture is its connection of language communications to architectural space in a biological manner. The designs of Zaha Hadid will be analyzed using this updated method. Most interpretations of her buildings focus on the spatial quality of her interiors and try to find contextual clues to explain the exterior shapes. This paper will propose a more scientific reading achieved by emphasizing the bodily and psychological contributions to an empathetic understanding.

Many contemporary buildings have rather unique symbolic properties. These are not based on conventional stylistic attributes, but consist primarily of forms. They are mostly derived from the characteristic Modern cubical shapes that are assembled of flat planes, which synthesize an understanding that assumes architecture is constituted like "human" bodies.

At the beginning of the Modern era, Alois Riegl (1858-1905) launched the concept of Kunstwollen, artistic volition, that exploited empathy as the mental capacity enabling us to conceive a spatial understanding from such designs. Riegl co-opted ideas proposed earlier by psychiatrists, artists, and art historians when he synthesized his own method. These earlier theorists had reacted to the change from figuration to abstraction that took place in the visual arts during the last decades of the 19th century. This would eventually become one of the roots of Modern form and design, and should have been used as a revelatory passage to the meaning of these forms. (Buchmann 2015, 36)

When analyzing art and architecture from the perspective of artistic volition, one sees them foremost as a social, not material, constructs. Riegl himself used this term also in his interpretation of buildings. He considered representation the primary task of art. Moreover, he favored the craft of carving over that of weaving, a judgement he used to state that artistic spirit is realized in matter, not ornament. (Vogt, Reble and Fröhlich 1976, 79) Riegl himself used this approach in three of his books. It is introduced in his Historical Grammar of the Visual Arts (1897-98). This was written as a polemic against the followers of Gottfried Semper, who had simplified the master's theory into the short statement that art works were created through functional efficiency, material choices, and efficient use of the material in constructing the final form. Against this pragmatic and materialistic interpretation of art, Riegl posited the artistic volition that determined the artistic outcome. For him, art serves three major needs, namely first to evoke ideas, second to satisfy our own decorative urge, and third, to serve functional purposes. (Riegl, Historical Grammar of the Visual Arts 2004, 61-62) In this respect, he purified art of extra-artistic considerations. By stating that art reveals its meaning only when a human being sees the work, he eliminated all sorts of rational and scientific attempts at deciphering.

Riegl then refined this concept in his book Late Roman Art Industry (1901), where the artistic volition begins to be defined through the formal choices and ornamental evolution of buildings and art works. In this book, Riegl deals extensively with Early Christian buildings, pointing out that these use flat planes for walls (Fig. 1).

When combined into a building, there are a lot of straight lines and edges that outline individual forms, which are following each other in a rhythmic sequence. These individual forms are then composed into material organic individuals, thus using the definition of the human body as analog for the architectural form. Flat planes were not only used in abstract paintings, but combined in architecture to enclose spaces. (Simons 2007, 161) In both cases, outlines and colors were the manifest physical parts that were analyzed in the interpretation of the work. Riegl stated this as "mankind meant to see 


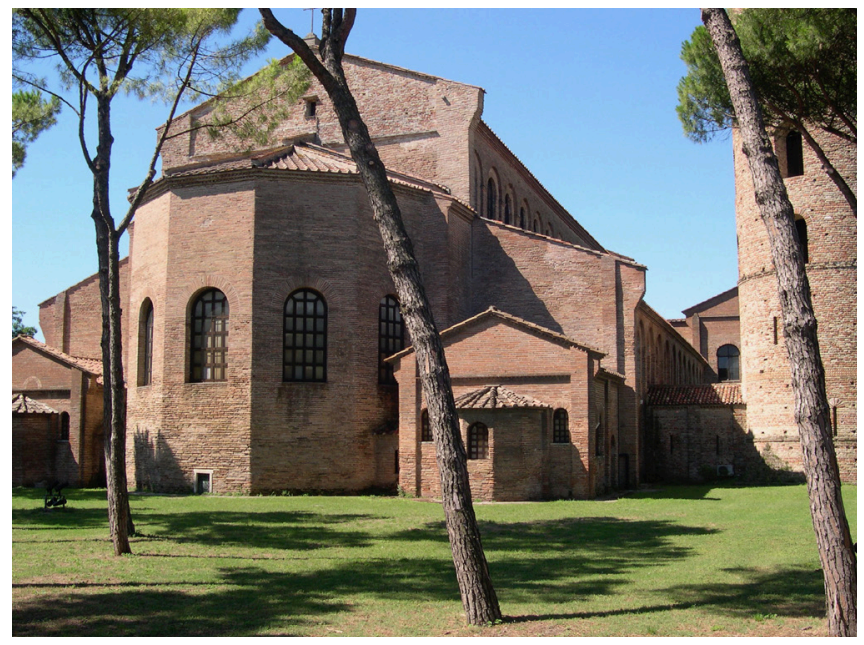

Figure 1: Sant'Appollinare in Classe, Ravenna (Author's Collection)

the visual appearances according to outlines and color on the plane or in space." (Preziosi 2009, 155-156)

Lastly, Kunstwollen is used in his The Creation of Baroque Art (1908). By now, it had evolved into a methodological term. In this book, it is mostly used to identify that the artist's volition is the ultimate reason for stylistic change. The focus on artistic volition facilitates the description of a work of art and the understanding of their structural organization. This obviously makes one's interpretation much clearer and convincing. (Simons 2007, 160)

From these books, it appears that when Kunstwollen is applied to architecture, it manifests itself primarily in the spaces building forms enclose. Spatial conceptions are different from one another based on the uses performed in the spaces and on the different civic significances determined by the world view of each age. Consequently, each age has its own artistic volition. (Simons 2007, 161-165)

However, Riegl's Kunstwollen did not have a significant impact on the interpretation (Arens 2007) of Modern Architecture. In hindsight, this is indeed surprising, because one could define abstract painting as consisting of forms and colors in a plane. Architecture just expands the latter into space.

To use this interpretative method for architecture is actually not such an outrageous thought. I got this idea from Katherine Arens's article "Stadtwollen: Benjamin's Arcades Project and the Problem of Method" of 2007. Arens is a professor of Germanic studies and comparative literature. In her publication, she examines Walter Benjamin's Arcades Project as object of study with Riegl's Kunstwollen as method of interpretation. She defines Stadtwollen as "the human drive to create a city as a structure of meaning." This was literally adapted from her reading of Kunstwollen as "a drive leading a culture to create works of art as structured artifacts ... that reveal an era's self-understanding." Arens transforms this into a distinct view of the city, namely as revealing not anything universal, but rather just as forms that "incorporate the given world" by an artist. She proposes that cities should be interpreted as "conditioned by ... human activity and existence," and consequently also as conditioning this same human existence. The city is understood "materiallyphenomenologically, when a concrete form actualizes a specific world understanding." The city seen in this way is then an "artifact demonstrating a Stadtwollen." (Arens 2007, passim) (Simmel 1968, passim)

Arens introduces a significant component of Kunstwollen, namely that people do not all think alike. Other scholars and theorists have expanded on this. In his essay "The work of art in the age of mechanical reproduction," Walter Benjamin promotes architecture as a medium that is directed toward the distracted urban crowd, since it is a form of art that is perceived best in an absentminded state. Urban architecture has always had an impact on city crowds. Buildings are understood and interpreted through their function and their form. We notice architecture in the city casually, i.e., not by paying particular attention to them. Like Riegl, Benjamin combines optical and haptic perception as the best way to become habituated to architecture. Distracted reception has become the preferred method of perception in the age of mechanical reproduction. (Benjamin 1936, Sect. XI)

Georg Simmel had similar ideas. In 1906, he published an essay titled: "On the Third Dimension in Art." He stated that depicting the third dimension in a two-dimensional medium is abnormal, because it is not really needed to create a convincing sensual perception. According to Simmel, depth cannot be perceived optically, only through tactile sensations. However, touching paintings would not create a more convincing perception of depth. Objects seen in painting are like ghosts. Hence, while a work of art is real, its meaning has a different kind of reality, namely an esthetic one. When viewing it, tactile sensations assist in understanding the optical perceptions. (Simmel 1968, passim)

In this manner, art historians have continued to elaborate Riegl's method. Since the 1960s, new perspectives have been proposed that have rendered empathy a valuable tool in furthering the interpretation of contemporary architecture. Recent research suggests that this method is now accepted as scientific. Since the method exploits human abilities, it is seen as leading to interpretations that bring architecture closer to human life. (Wagner 2009, 49) This perspective fits into the evolution of the sciences during the last few decades of the 19th century. The then reigning method of collecting, viewing, and cataloguing of monuments was not sufficient to legitimize art history as a science. Riegl developed art history into one of the descriptive sciences with laws analogous to those in the natural sciences. Such efforts have evolved art history from a transcendental perch down to concern with 


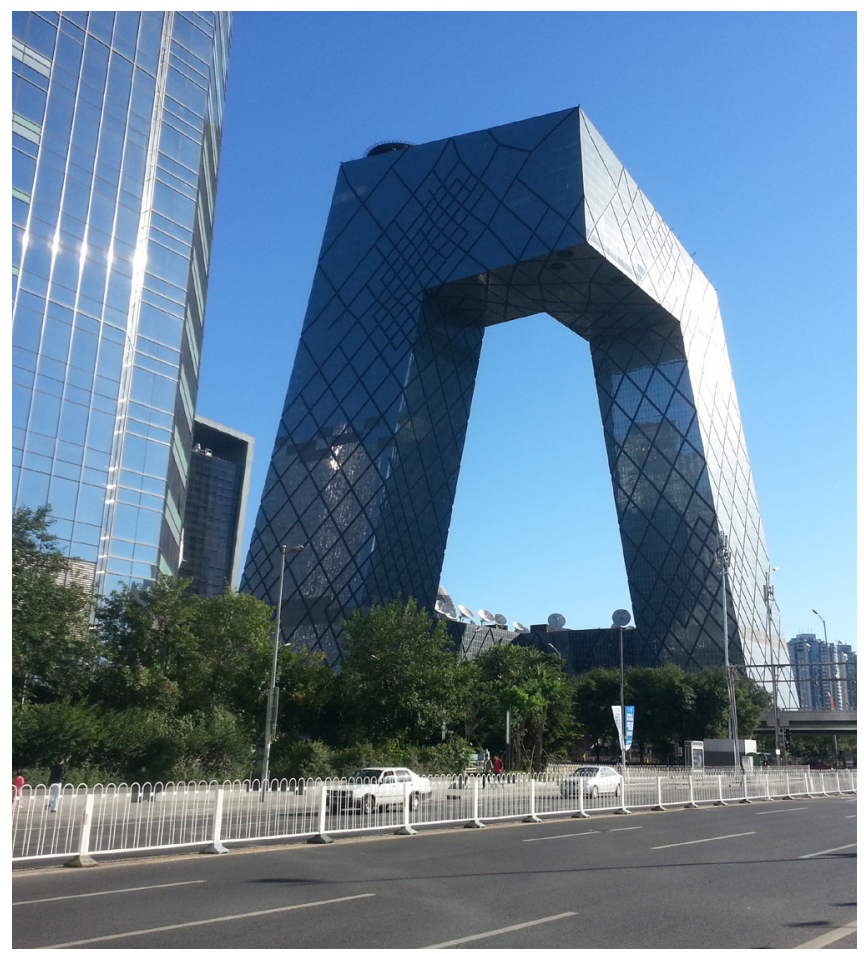

Figure 2: CCTV Building, Beijing, 2004-2012 (Creative Commons Attribution-Share Alike 3.0 Unported)

physiological perception and ability. Whereas previously art history was seen as developing cyclically through periods of growth and decay, Riegl gave it a truly evolutionary trajectory. (Noll n.d., 187)

Interestingly, the philosopher Paul Feyerabend wrote a book in 1984 titled Science as Art, in which he tried to reverse-engineer Riegl's art historical method of Kunstwollen back to the exact sciences. Feyerabend was intrigued by the scientific nature of Riegl's ideas. Riegl took issue with the concept that art was always evolving in cycles of progress followed by decay. Instead of this cyclical view, he posited that there are only styles, and that art history is the story of their succession. (Feyerabend 1984, 29)

Riegl's theory has always been considered to be a part of formal esthetics, and as such its primary method was descriptive. Of course, when proceeding toward interpretation, there must also be an additional intellectual process. Immanent formal relationships in a work of architecture are grasped in the transitions between individual parts. These are rationally analyzed and become the esthetically significant elements of a building. Such elements are formed of clearly delineated surfaces that are seen in a haptic manner, meaning that the viewer uses memories of touch to completely understand what is seen.

Feyerabend realized that Riegl had grasped that art has nothing to do with reality. With regard to science, he considered mathematics the equivalent of Riegl's "art" and saw both as means to construct fantasy worlds, and hence tools to explore reality. (Feyerabend 1984, 38) Art offers us a view of reality that is defined by our way of thinking. (Feyerabend 1984, 46) It is this difference between reality and art that is interesting for my investigation.

The mental construction of reality is not a direct translation of natural reality, but informed by aspirations, desires, memories, traditions, and customs. A crucial point is also the extent of what human beings know about their natural environment, and whether this knowledge is based on scientific definitions or social conventions. The question is whether the artistic reality should be rational and abstract or irrational and realistic? (Feyerabend 1984, 54-76)

The answer is simple: understanding a work of art is determined by Kunstwollen. The fantasy world generated through art is influenced by the psychology of the viewer. Moreover, artistic design is not possible without solving problems through deliberate decisions. Most works of art and architecture deal with form, so one could say that forms can only be explained as the result of an artistic will. However, these definitions no longer work when art is produced in more recent media than those available in Riegl's time. Film and video, e.g., are not static, but show a sequence, or a development. Here, forms are less important than visibility. In these media, reality is simulated, and the art works cease to be pictures. In the so far latest incarnation of the new media-cyberspace-there is not even a physical reality any more. At the same time, however, cyberspace is also no longer symbolic. The equivalent of this in architecture is Computer-Aided Design. CAD designs, or pictures, should therefore be treated as information, not as expression. Nevertheless, even CAD images still result from a particular way of seeing, namely the artist's way of seeing. Ultimately, art represents reality in a way that can be understood by many people. This is because it respects the way in which we humans see and understand the world around us.

Riegl's explanation of Kunstwollen and the definitions of what we see clearly instituted a "Flächenraum" (flat space) as the category of space found in both painting and architecture. What flat space is can be explained through a number of 20thcentury paintings. One could use Jasper Johns's typical Flag paintings as excellent examples to illustrate this, because while they do show a flag, they can also be understood as abstract compositions consisting of differently colored geometric areas. The critic Clement Greenberg established planarity as the main characteristic of Modern art, but stated that these paintings nevertheless have also a spatial dimension. An example of this would be a typical Cubist painting, where the individual forms do have a spatial appearance.

Jackson Pollock's paintings with their superimposed drip lines could also incite us to read them as portraying a spatial feeling. 


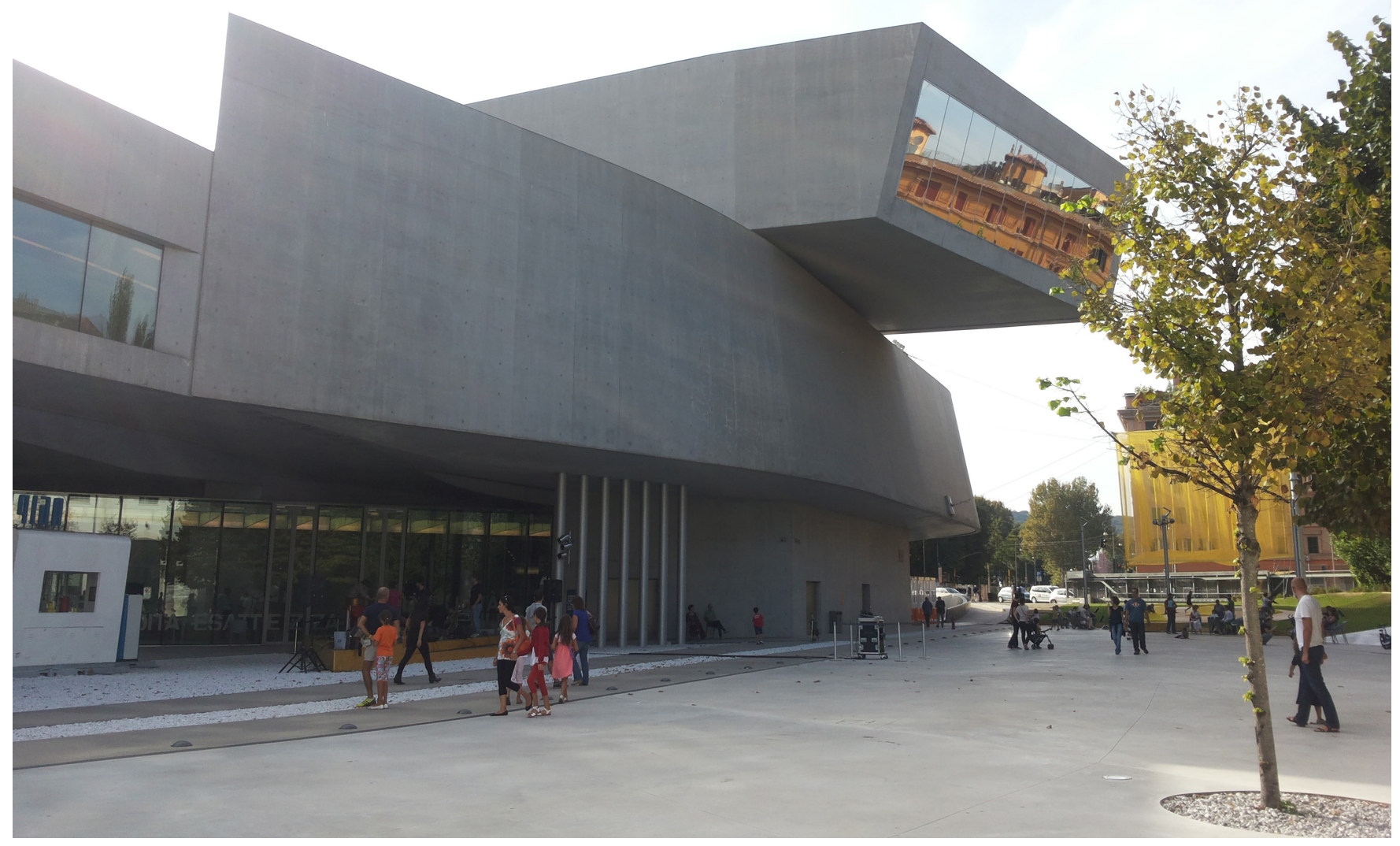

[Figure 3: MAXXI Museum, Rome, 2012 (Creative Commons Attribution 4.0 International License)

Minimal art then abandons this content and emphasizes pure opticality, where the physical work is secondary to its optical impression. These works now address purely the viewer's phenomenological capacities. (for the above information see Regine Pranger, "Konjunkturen des Optischen," in (Peter Noever 2010), 109-124)

Margaret Olin's article "Was bleibt von Riegl's Theorie: Riegl auf Amerikanisch," deals with photography, especially how the haptic view has transformed-through the smart phone cameras-into the acceptance of photographs as better proof of life than real life. This is obviously a stab at the selfie. (Margaret Olin, in (Peter Noever 2010), 129-136)

The most important lesson from Riegl's theory is that the viewer sees via a bodily experience and synthesizes an understanding of his own Being through this perception. One could say that through empathetic perception abstraction is connected to reality. Since this is an interpretative method that does not deal with content, it helps to regulate the relationship between human beings and the world. Art understood in this perspective does not represent, but presents psychic, primordial drives, turning this enterprise into a psycho-physiological experience.
This conception of the fully developed three-dimensional space coincides with the purely optical world view we have begun to favor during the past few decades. For Riegl, works of art engender a mood in the viewer. (Riegl 1929) In his own time, this mood was seen as leading to a state of harmony. (Simons, 167)

Emphasizing space in architectural perception allows the viewer to literally step into the building, before actually enter it physically. (Simons, 176)

Elevating space to one of the significant agents that leads to architectural understanding has appeared here and there in German 19th-century architectural theory. A case in point is Arnold Göller's essay “What is the Cause of Perpetual Change in Architecture?" of 1887. He begins by stating that architectural perception is both intellectual and esthetic, defining the latter as "an inherently pleasurable, meaningless play of lines or of light and shade." Thus, architecture offers us abstract, geometric forms that do not remind us of objects. Consequently, architectural form pleases without the viewer thinking much about content. Architecture is then "the true art of pure visible form." We see an architectural form and convey this perception to our minds, where a conception or image is formed. In this conscious imaging, pleasure appears. (Göller, in (Getty Center for the History of Art and the Humanities 1994), 193-226) 


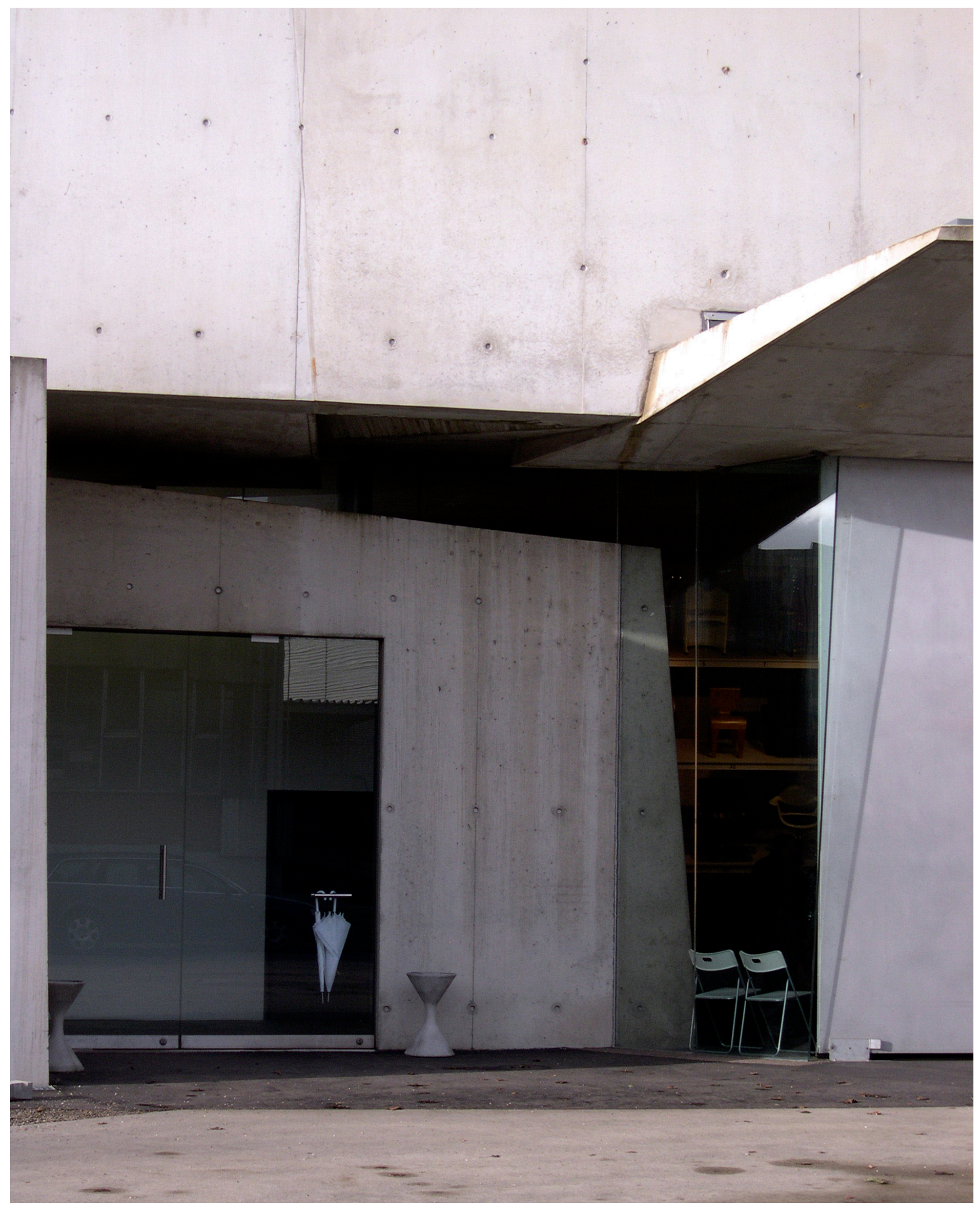

Figure 4: Vitra Fire Station, Weil am Rhein, 1987-1993 (Author's Collection). 


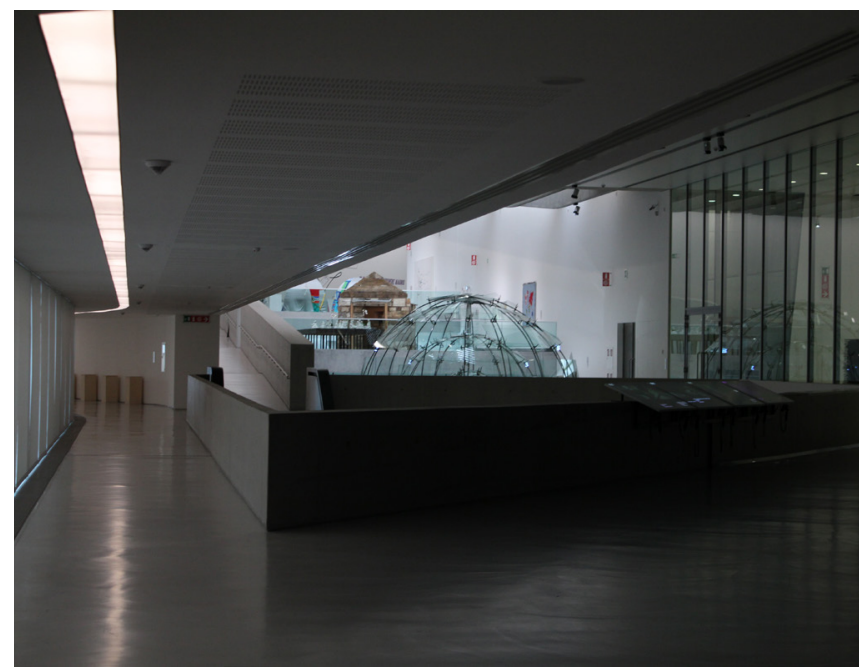

Figure 5: Interior shot of the Maxxi Museum

When we look at contemporary buildings, the main impression we take away seems to be the spatial array. Our technological skill is so advanced that practically any form can be constructed, such as shown in the CCTV Building in Beijing (Fig. 2). According to Riegl's method, we retrieve the spatial configuration optically from the exterior formal composition of a building. Then, we must formulate a thorough linguistic description of what we see. This transformation of the visual perception into an intellectual conception seems to me to be the most important task in understanding and interpreting a building according to the "architectural volition" method. This will bring out clearer and more convincing building critiques and evaluations. The active cooperation between the viewer and a building might present an interesting way to deal with contemporary architecture.

During the 19th century, force was a term widely used in esthetics. In architectural interpretation, forms were read as reacting to forces. This applied primarily to Art Nouveau buildings. The viewer perceives these forces through empathy. This helps him/her objectivize their feeling of self. Through empathy, one perceives the movement, through empirical analysis one interprets this as a mechanical force. This has repercussion on the architect's work, because it would limit the amount of free design he/she can achieve. Art is made for seeing, hence lines need to mean something, and not just be beautiful. Good art produces clear lines.

This focus on lines is needed because today, style is no longer a particularly useful perspective for architectural history and interpretation. Contemporary architectural forms are assembled of various surfaces that are in most cases delineated and bound by lines. These create a visual scaffolding, a cage, which we use to imbue with dynamism that we then translate into movement energy. It is extremely necessary that the viewer's sensual perception becomes a mental imagination and an intellectual concept, which can then be communicated through language. Only through this action will it become a reality that is commensurate with human physique. In other words, this produces a sensual recreation of a work of art.

So, one could expect from the artist that he/she recreate what they see. The viewer then sees exactly that. With regard to the architect, one expects that what one sees is what one should interpret.

This will bring out clearer and more convincing building critiques and evaluations. The active cooperation between the viewer and a work of art, or for my own purposes, a building, might present an interesting way to deal with contemporary architecture. I would like to use the designs of Zaha Hadid to make this point. I have always been frustrated by the reactions of architectural critics to her designs. Most scholarly texts on deconstructivist architecture attempt fruitlessly to connect a philosophical point of view to an architectural form. In the case of the Vitra Fire Station (Fig. 4), for instance, we read analyses that attempt to explain the skewed composition of this building as deriving from the obliquely viewed rectangular fields nearby that then magically congregated into this design. Or the forms are explained as having been pushed out of the earth by natural eruptions. Such rational explanations of a highly subjective creative process are disappointing. This building really transcends the restrictions architectural construction usually has to follow, such as the structural potential of building materials, functional considerations, as well as, form and ornamental design conventions. Should we not try instead to understand this building through the search for the architectural volition that generated it? What if Hadid simply wanted to create an unusual building that requires its users to be constantly attentive to their environment. Maybe this building intended to keep the firefighters alert at all times, so that they would see the next fire in time to extinguish it before it destroyed the factory again?

In the case of the MAXXI National Museum of the 21st Century Arts in Rome (Fig. 3), she might have intended to show its visitors the complex and multidisciplinary flows of future art. And yet, critics have boasted that it is not a container, but a campus. They faithfully describe how "pathways flow and overlap to create a dynamic and interactive space," which we then have to accept as an interpretation (Fig. 5). The question whether a deconstructivist building fits into a static cityscape is left unanswered. Nonsensical statements like "the curved walls of the museum dialogue with neo-classical symmetrical façades" are left hanging. (Giannotti 2009) The architect's design is called "spatial experimentation" and "Piranesian," as if any non-architect knew what that means. (Woodman 2010) The building is compared to a circuit board, but also qualified as muscular and visceral. (The Architectural Review n.d.) 
If the idea of a "Kunstwollen" would be used in architectural interpretation, we would read forms not for what they are, but for how they feel. Above all, we would analyze forms for what they tell us about the flow of space. People would learn instinctually how to move through a space and this space would feel familiar to them. Their perception of a space would be automatically transformed into the incentive to start walking and fill the space with their own personality and understanding. Empathetic understanding of architectural forms negates the use of maps or other instructions on how to move through a space.

It is highly feasible, that the entire history of 20th-century architecture, beginning with Modernism, might benefit from being investigated anew from the perspective of an architectural volition. There are too many highly complex, sometimes even esoteric, attempts at deciphering buildings through methods that are brought in by other discipline into historiography. Instead, as Riegl advises us to do, sometimes one learns more through a thorough description of the building, which is then completed through a psychological reading of these forms. If one looks attentively at two interiors, e.g. House Lange by Mies van der Rohe, and Villa Savoye by Le Corbusier, one can see the different intentions of these two architects quite easily. Mies created an open unobtrusive interior, whereas Le Corbusier tightly controls how one ascends from the entrance hall to the upper floor.

\section{BIBLIOGRAPHY}

1 Arens, Katherine. "Stadtwollen: Benjamin's "Arcades Project" and the Problem of Method." PMLA (Modern Language Association) 122, no. 1 (Jan. 2007): 43-60.

2 Buchmann, Sabeth \& Frank, Rike. Textile Theorien der Moderne: Alois Riegl in der Kunstkritik. Berlin: PoLYpeN, 2015.

3 Feyerabend, Paul. Wissenschaft als Kunst. Frankfurt am Main: Suhrkamp Verlag, 1984.

4 Getty Center for the History of Art and the Humanities. Empathy, Form, and Space: Problems in German Aesthetics 1873-1893. Santa Monica: Getty, 1994).

5 Newhouse, Victoria. Chaos and Culture. (New York: Monacelli, 2017).

6 Noll, Thomas. Ordnungsmodelle in der Kunstgeschichte. Von Bocaccio, Alberti und Vasari zu Kugler und Riegl. Vol. 1, in Geschichtsentwürfe und Identitätsbildung am Beginn der Neuzeit, by Ludger Grenzmann, \& Burkhard, and Rexroth, Frank Hasebring, 158-187. Berlin: De Gruyter, n.d.

7 Peter Noever, Artur Rosenauer, and Georg Vasold. AloismRiegl Revisited. (Wien: Österreichische Akademie der Wissenschaften, 2010).

8 Preziosi, Donald. The Art of Art History. (New York: Oxford University Press, 2009).

9 Riegl, Alois. "'Die Stimmung as Inhalt der modernen Kunst"." In Alois Riegl, Gesammelte Aufsätze, by Alois Riegl, 31-34. Augsburg-Wien: Dr. Benno Filser Verlag, $\mathrm{GmbH}, 1929$.

10 Simmel, Georg. "On the Third Dimension in Art." In The Conflict in Modern Culture and Other Essays, by Georg Simmel, 88-90. New York: Teachers College Press, 1968.

11 Simons, Oliver. Raumgeschichten. (München: Wilhelm Fink Verlag, 2007).

12 The Architectural Review.n.d.

13 Vogt, Adolf Max, Christina Reble, and Martin Fröhlich. Gottfried Semper und die Mitte des 19. Jahrhunderts. Basel: Birkhäuser, 1976.

14 Wagner, Kirsten. "Die Beseelung der Architektur: Empathie und Architektonischer Raum." In Einfühlung: Zur Geschichte und Gegenwart eines ästhetischen Konzepts, by Robin and Koch, Gertrud Curtis, 49-78. Paderborn Wilhelm Fink, 2009.

15 Woodman, Ellis. "'MAXXI Museum"." The Telegraph, May 24, 2010.

\section{LIST OF ILLUSTRATIONS}

Fig. 1: KUBUS Extension to Historisches Museum, Bern, mlzd Architects (2006-2009) [Author's collection]

Fig. 2: Sant'Appollinare in Classe, Ravenna (532-549) [Author's collection]

Fig. 3: CCTV Building, Beijing, OMA (2004-2012) [Creative Commons AttributionShare Alike 3.0 Unported]

Fig. 4: Vitra Fire Station, Weil-am-Rhein, Zaha Hadid (1987-1993) [Author's collection]

Fig. 5: MAXXI Museum, Rome, Zaha Hadid (2010) [Creative Commons Attribution 4.0 International License]

Fig. 6: MAXXI Museum, Rome, Zaha Hadid, Interior (2010) [Wikimedia Commons, By Commonurbock23, CC BY-SA 3.0 License] 2016): 170. 